\title{
Does place of residence affect patient satisfaction with hospital health care?
}

\author{
Dominik Maślach ${ }^{1, A-B, D-F \oplus}$, Bogusława Karczewska, ${ }^{1, B-E \oplus}$, Andrzej Szpak ${ }^{2, E-F}{ }^{\oplus}$, \\ Angelika Charkiewicz ${ }^{1, \mathrm{E}-\mathrm{F}}$, Michalina Krzyżak ${ }^{3, \mathrm{E}-\mathrm{F}}$ \\ ${ }^{1}$ Department of Public Health, Faculty of Health Sciences, Medical University of Bialystok, Poland \\ 2 Department of Epidemiology and Biostatistics, Institute of Rural Health, Lublin, Poland \\ ${ }^{3}$ Department of Hygiene, Epidemiology and Ergonomics, Faculty of Health Sciences, Medical University of Bialystok, \\ Poland \\ A - Research concept and design, B - Collection and/or assembly of data, C - Data analysis and interpretation, \\ $D$ - Writing the article, E - Critical revision of the article, $F$ - Final approval of article
}

Maślach D, Karczewska B, Szpak A, Charkiewicz A, Krzyżak M. Does place of residence affect patient satisfaction with hospital health care? Ann Agric Environ Med. 2020; 27(1): 86-90. DOI: 10.26444/aaem/116574

\section{Ibstract}

Introduction and objective. Measuring the level of patient satisfaction is a useful tool in delivering quality care that is responsive to consumer preferences. Various socio-demographic factors might be considered as potential predictors of patient satisfaction. The aim of the study was to assess whether place of residence (rural/urban) affects patient satisfaction with hospital health care.

Materials and method. Data were obtained using face-to-face questionnaire, administered in five large, urban hospitals in Podlaskie Province, north-eastern Poland, during 2014-2018. The study sample comprised of 1,624 participants (585 rural, 1039 urban) who assessed satisfaction with 28 hospital health care items. The means and standard deviations were presented to compare 28 satisfaction items between the rural and the urban samples. Regression analysis was used to determine whether location difference (rural vs urban) affected patient satisfaction with various domains of hospital health care.

Results. The mean results of 28 satisfaction items on the 1-5 scale were similar among the rural and the urban samples, and generally skewed towards positive experiences. In the univariate analysis, significant associations between place of residence and patient satisfaction were identified with regard to three components of inpatient care: 1) hospital settings and staff care, 2) doctors' professional skills, and 3) hospitalization outcomes. After adjusting for socio-demographic variables, the association remained significant only with respect to satisfaction with hospitalization outcomes $(b=0.121 ; S E=0.055$; $p=0.028$ )

Conclusions. Some evidence for differences in patient satisfaction by place of residence was found. Study findings may be helpful in implementing care quality improvement programmes.

\section{Key words}

patient satisfaction, hospital health care, health care services, care quality, rural, urban

\section{INTRODUCTION}

The current healthcare system is becoming increasingly consumer-driven as more and more often health care providers take into account patients' opinions and expectations. Measuring the level of patient satisfaction is a useful tool in delivering quality health care that is responsive to consumer preferences $[1,2]$. Patient satisfaction can also be helpful in predicting utilization and compliance as satisfied consumers are more likely to continue using health care services and follow medical regimens [3].

Patient satisfaction can be viewed as related to the degree to which patient expectations are being met. If expectations of quality care are not fulfilled, reported satisfaction will be low. Conversely, when the offered care exceeds patient expectations, the level of satisfaction will be high $[4,5]$. The most important components of patient satisfaction are health care service quality indicators [6], among which health providers' interpersonal care quality seems to be of

Address for correspondence: Bogusława Karczewska Department of Public Health, Faculty of Health Sciences, Medical University, Bialystok, Poland

E-mail: boguslawa.karczewska@umb.edu.pl

Received: 30.10.2019; accepted: 13.01.2020; first published: 31.01 .2020 major importance $[7,8,9]$. There is a strong evidence for the influence of doctor-patient relationship on different aspects of health outcomes, as modification in doctors' communication style can have positive effects on the patients' health status, compliance, and quality of life [10].

Various socio-demographic factors might be considered as potential predictors of patient satisfaction, e.g. gender, age, social class, marital status, or place of residence $[11,12]$. However, with the exception of age, the findings about the relationship between patients' background characteristics and satisfaction are inconsistent [11].

Despite a growing homogenization of modern societies, some disparities in the health experiences can still be identified based on people's place of residence: rural or urban. For instance, accessibility to needed care is more challenging in the rural population [13-16], whereas urban residents tend to have higher expectations regarding care quality [17, 18]. Consequently, different expectations and utilization of healthcare services between rural residents and their urban counterparts [19-23] may lead to differences in satisfaction outcomes $[3,17,24]$. 


\section{OBJECTIVE}

The aim of the study was to examine whether place of residence (rural/urban) differentiates patient assessment of satisfaction with hospital health care.

\section{MATERIALS AND METHOD}

The study was conducted in 2014-2018, in 5 public hospitals located in the main cities of the Podlaskie Province in northeastern Poland: Białystok (3 hospitals), Łomża (1 hospital), and Suwałki (1 hospital). The study involved performing 3 face-to-face surveys at 2-year-intervals $(2014,2016,2018)$ at the respective hospitals. The questionnaire was modelled on a scale used to assess the quality of primary health care [25]. The tool was adapted and extended to include specificities of health care provided by in-patient units. The questionnaire contained 28 satisfaction items covering numerous aspects of in-patient care. All of the items had a 5-point scale ranging from 'negative' scored as 1 to 'positive' scored as 5. The questionnaire also included the respondents' background variables: gender, age, education level, professional status, and place of residence. The study was approved by the Bioethics Committee of the Medical University of Białystok.

Study sample. Adult patients were recruited from randomly chosen hospital departments and interviewed during their stay at the respective hospitals. The initial study sample consisted of 1,858 participants; however 234 respondents had to be excluded due to missing data on the main scale. Eventually, the study group included 1,624 participants, of whom 585 (36.0\%) were rural patients and 1,039 (64.0\%) were urban patients.

Data analysis. The statistical analysis was carried out by means of IBM SPSS Statistics v. 20. Descriptive statistics were presented for the respondents' socio-demographic characteristics. In the first step of the comparative analysis, means and standard deviations were presented for the assessment of data referring to satisfaction with 28 inpatient care items on the 1-5 scale. Next, 28 satisfaction items were entered into an exploratory factor analysis with varimax rotation to uncover the underlying structure of the questionnaire. Loadings of 0.45 or higher were considered significant in the interpretation of the factor matrix. Univariate linear regression analysis of identified factors was then used to examine whether place of residence affects patient satisfaction. Finally, multivariable linear regression models were run to assess the impact of adjusting for sociodemographic characteristics to determine whether the location difference (rural vs urban) independently affects patient satisfaction. Multivariable models included the following socio-demographic variables as covariates: gender, age (in years), education level, and professional status. In order to identify statistically significant differences between the rural and urban samples, the chi-square test and the Mann-Whitney $U$-test were used. For all the statistical tests used, a $\mathrm{p}$ value of $<0.05$ was considered statistically significant.

\section{RESULTS}

Participants' characteristics. There were significant differences between the rural and the urban samples with regard to gender, age, education, and professional status. In comparison with their urban counterparts, rural patients were less female-dominated, slightly older, and to a lesser extent educated and employed. Detailed comparison of sociodemographic characteristics between the rural and the urban samples are shown in Table 1.

Table 1. Socio-demographic characteristics of participants

\begin{tabular}{|c|c|c|c|c|c|c|}
\hline & & \multicolumn{2}{|c|}{ Rural sample } & \multicolumn{2}{|c|}{ Urban sample } & \multirow{2}{*}{$\mathrm{p}$} \\
\hline & & $N$ & $\%$ & $N$ & $\%$ & \\
\hline \multirow{2}{*}{ Gender } & female & 320 & 54.8 & 625 & 60.2 & \multirow{2}{*}{0.034} \\
\hline & male & 264 & 45.2 & 413 & 39.8 & \\
\hline \multirow{5}{*}{ Age (years) } & $15-24$ & 27 & 4.6 & 68 & 6.5 & \multirow{5}{*}{0.013} \\
\hline & $25-34$ & 71 & 12.1 & 161 & 15.5 & \\
\hline & $35-44$ & 50 & 8.5 & 119 & 11.5 & \\
\hline & $45-64$ & 230 & 39.3 & 380 & 36.6 & \\
\hline & 65 and over & 207 & 35.4 & 311 & 29.9 & \\
\hline \multirow{4}{*}{$\begin{array}{l}\text { Education } \\
\text { level }\end{array}$} & elementary & 188 & 32.2 & 105 & 10.2 & \multirow{4}{*}{$<0.001$} \\
\hline & technical & 163 & 28.0 & 206 & 19.9 & \\
\hline & secondary & 168 & 28.8 & 458 & 44.3 & \\
\hline & university & 64 & 11.0 & 264 & 25.6 & \\
\hline \multirow{5}{*}{$\begin{array}{l}\text { Professional } \\
\text { status }\end{array}$} & In education & 14 & 2.4 & 35 & 3.4 & \multirow{5}{*}{$<0.001$} \\
\hline & employment & 198 & 33.9 & 463 & 44.6 & \\
\hline & disability pension & 109 & 18.7 & 114 & 11.0 & \\
\hline & retirement & 36.5 & 213 & 33.7 & 350 & \\
\hline & unemployment & 50 & 8.6 & 77 & 7.4 & \\
\hline
\end{tabular}

In most cases, mean results for the 28 satisfaction items were similar among the rural and the urban patients (Tab. 2). In general, item means were skewed towards positive experiences of care ranging from $4.20-4.84$ on the $1-5$ scale. Regardless of the place of residence, patients had the poorest experiences with waiting time in a hospital admission unit, and the best experiences with a doctor being respectful. Significant differences in satisfaction between the rural and the urban patients were identified in relation to 9 items. In all 9 cases, rural respondents ranked the respective items slightly higher than their urban counterparts.

Exploratory factor analysis, run on the patient satisfaction items, revealed that a 5-factor solution fit the data well (Tab. 3). The items that loaded on the first factor pertained to doctors' interpersonal skills (e.g. doctor being polite, friendly, respectful). The second factor was made by different aspects of patients' empowerment (e.g. motivation to follow the recommended treatment, ability to respond in case of deterioration of health, patient involvement in treatment decisions). The third factor described satisfaction with hospital settings and staff care (e.g. patients' treatment by nurses and auxiliary staff, conditions on a ward). The fourth factor pertained to doctors' professional skills (e.g. correct diagnosis made by a doctor, proper choice of additional tests ordered by a doctor). The fifth factor indicated satisfaction with hospitalization outcomes (e.g. improvement in health condition and emotional state). The 5 factors accounted for $63.16 \%$ of the total variance explained (Factor 1:22.44\%; Factor 
Table 2. Assessment of patient satisfaction items on the 1-5 scale comparison between rural and urban samples

\begin{tabular}{|c|c|c|c|c|c|}
\hline \multirow[t]{2}{*}{ Items } & \multicolumn{2}{|c|}{$\begin{array}{c}\text { Rural } \\
\text { sample }\end{array}$} & \multicolumn{2}{|c|}{$\begin{array}{l}\text { Urban } \\
\text { sample }\end{array}$} & \multirow[t]{2}{*}{$\mathrm{p}$} \\
\hline & M & $S D$ & M & $S D$ & \\
\hline 1. Waiting time in hospital admission unit & 4.36 & 1.10 & 4.20 & 1.15 & 0.002 \\
\hline $\begin{array}{l}\text { 2. Conditions on ward (cleanliness, food } \\
\text { quality, etc.) }\end{array}$ & 4.63 & 0.74 & 4.49 & 0.86 & $<0.001$ \\
\hline 3. Doctor is polite and friendly & 4.83 & 0.52 & 4.82 & 0.54 & 0.792 \\
\hline 4. Doctor is respectful & 4.84 & 0.51 & 4.83 & 0.50 & 0.401 \\
\hline 5. Doctor is reassuring & 4.75 & 0.63 & 4.74 & 0.65 & 0.574 \\
\hline $\begin{array}{l}\text { 6. Patient's privacy is respected during } \\
\text { examination }\end{array}$ & 4.81 & 0.58 & 4.81 & 0.54 & 0.685 \\
\hline $\begin{array}{l}\text { 7. Doctor is attentive (encourages patient to } \\
\text { talk about problems and concerns) }\end{array}$ & 4.76 & 0.65 & 4.73 & 0.68 & 0.099 \\
\hline $\begin{array}{l}\text { 8. Explanation of a health problem was clear } \\
\text { and complete }\end{array}$ & 4.71 & 0.73 & 4.66 & 0.79 & 0.170 \\
\hline $\begin{array}{l}\text { 9. Explanation of ordered tests was clear and } \\
\text { complete }\end{array}$ & 4.72 & 0.72 & 4.68 & 0.73 & 0.165 \\
\hline $\begin{array}{l}\text { 10. Explanation of chosen treatment was } \\
\text { clear and complete }\end{array}$ & 4.70 & 0.77 & 4.65 & 0.76 & 0.093 \\
\hline $\begin{array}{l}\text { 11. Patient involvement in treatment } \\
\text { decisions }\end{array}$ & 4.76 & 0.58 & 4.70 & 0.65 & 0.076 \\
\hline $\begin{array}{l}\text { 12. Time spent on consultations with a } \\
\text { doctor }\end{array}$ & 4.70 & 0.70 & 4.61 & 0.78 & 0.010 \\
\hline $\begin{array}{l}\text { 13. History of the health problem is taken } \\
\text { into account by a doctor }\end{array}$ & 4.79 & 0.59 & 4.75 & 0.70 & 0.305 \\
\hline $\begin{array}{l}\text { 14. Doctor's skills in making the medical } \\
\text { examination more comfortable }\end{array}$ & 4.71 & 0.64 & 4.69 & 0.66 & 0.460 \\
\hline $\begin{array}{l}\text { 15. Proper choice of additional tests ordered } \\
\text { by a doctor }\end{array}$ & 4.62 & 0.72 & 4.55 & 0.82 & 0.176 \\
\hline 16. Correct diagnosis made by a doctor & 4.66 & 0.70 & 4.55 & 0.80 & 0.022 \\
\hline $\begin{array}{l}\text { 17. Performing care and conducting } \\
\text { treatment by a doctor }\end{array}$ & 4.75 & 0.61 & 4.73 & 0.62 & 0.530 \\
\hline $\begin{array}{l}\text { 18. Possibility of repeated consultations with } \\
\text { the same doctor }\end{array}$ & 4.70 & 0.69 & 4.63 & 0.75 & 0.139 \\
\hline 19. Waiting time for diagnostic test results & 4.65 & 0.68 & 4.55 & 0.82 & 0.055 \\
\hline $\begin{array}{l}\text { 20. Improvement in health condition } \\
\text { (reduced symptoms, pain) }\end{array}$ & 4.53 & 0.83 & 4.37 & 0.92 & $<0.001$ \\
\hline $\begin{array}{l}\text { 21. Improvement in emotional state } \\
\text { (reduced fears, concerns) }\end{array}$ & 4.46 & 0.92 & 4.36 & 0.95 & 0.030 \\
\hline 22. Return to routine activities & 4.47 & 0.88 & 4.42 & 0.91 & 0.258 \\
\hline $\begin{array}{l}\text { 23. Ability to respond in case of deterioration } \\
\text { of health (what to do, who to contact) }\end{array}$ & 4.72 & 0.64 & 4.68 & 0.72 & 0.337 \\
\hline $\begin{array}{l}\text { 24. Motivation to follow recommended } \\
\text { treatment }\end{array}$ & 4.76 & 0.56 & 4.74 & 0.64 & 0.964 \\
\hline 25. Treatment of patients by auxiliary staff & 4.80 & 0.54 & 4.70 & 0.65 & 0.001 \\
\hline 26. Waiting time for diagnosis and treatment & 4.72 & 0.66 & 4.66 & 0.75 & 0.175 \\
\hline $\begin{array}{l}\text { 27. Nurses' professionalism and their } \\
\text { relations with patient (kindness, patience, } \\
\text { diligence) }\end{array}$ & 4.80 & 0.56 & 4.75 & 0.58 & 0.037 \\
\hline $\begin{array}{l}\text { 28. Providing information about disease } \\
\text { prevention and a healthy lifestyle by a } \\
\text { doctor or nurse }\end{array}$ & 4.68 & 0.76 & 4.59 & 0.83 & 0.022 \\
\hline
\end{tabular}

Results in bold are significant at $p<0.05$

2: 13.10\%; Factor 3: 10.44\%; Factor 4: 9.13\%; Factor 5: 8.03\%).

The identified factors were then used in regression analysis as dependent variables. Two models (univariate and multivariate) were constructed for each factor (Tab. 4). Significant associations between location difference (rural vs
Table 3. Varimax rotated factor loadings of patient satisfaction items on the 5 factors

\begin{tabular}{|c|c|c|c|c|c|}
\hline \multirow{2}{*}{ Items } & \multicolumn{5}{|c|}{ Factors } \\
\hline & 1 & 2 & 3 & 4 & 5 \\
\hline 1. Waiting time in hospital admission unit & 0.07 & 0.20 & 0.32 & 0.12 & 0.07 \\
\hline $\begin{array}{l}\text { 2. Conditions on a ward (cleanliness, food } \\
\text { quality etc.) }\end{array}$ & 0.25 & 0.12 & 0.55 & 0.18 & 0.06 \\
\hline 3. Doctor is polite and friendly & 0.80 & 0.09 & 0.34 & 0.10 & 0.06 \\
\hline 4. Doctor is respectful & 0.79 & 0.07 & 0.34 & 0.11 & 0.06 \\
\hline 5. Doctor is reassuring & 0.73 & 0.24 & 0.30 & 0.13 & 0.05 \\
\hline $\begin{array}{l}\text { 6. Patient's privacy is respected during } \\
\text { examination }\end{array}$ & 0.62 & 0.34 & 0.24 & 0.02 & 0.02 \\
\hline $\begin{array}{l}\text { 7. Doctor is attentive (encourages patient to } \\
\text { talk about problems and concerns) }\end{array}$ & 0.75 & 0.30 & 0.26 & 0.06 & 0.06 \\
\hline $\begin{array}{l}\text { 8. Explanation of a health problem was clear } \\
\text { and complete }\end{array}$ & 0.74 & 0.16 & 0.02 & 0.26 & 0.24 \\
\hline $\begin{array}{l}\text { 9. Explanation of ordered tests was clear and } \\
\text { complete }\end{array}$ & 0.77 & 0.14 & 0.03 & 0.26 & 0.22 \\
\hline $\begin{array}{l}\text { 10. Explanation of chosen treatment was clear } \\
\text { and complete }\end{array}$ & 0.74 & 0.19 & 0.03 & 0.25 & 0.26 \\
\hline 11. Patient involvement in treatment decisions & 0.37 & 0.61 & 0.10 & 0.07 & 0.02 \\
\hline 12. Time spent on consultations with a doctor & 0.61 & 0.42 & 0.16 & 0.26 & 0.08 \\
\hline $\begin{array}{l}\text { 13. History of the health problem is taken into } \\
\text { account by a doctor }\end{array}$ & 0.49 & 0.33 & 0.12 & 0.18 & 0.08 \\
\hline
\end{tabular}

14. Doctor's skills in making the medical

examination more comfortable

$\begin{array}{lllll}\mathbf{0 . 4 7} & 0.30 & 0.15 & \mathbf{0 . 4 8} & 0.06\end{array}$

15. Proper choice of additional tests ordered by a doctor

$\begin{array}{lllll}0.23 & 0.14 & 0.16 & \mathbf{0 . 8 0} & 0.09\end{array}$

16. Correct diagnosis made by a doctor

$\begin{array}{lllll}0.20 & 0.10 & 0.13 & \mathbf{0 . 8 2} & 0.16\end{array}$

17. Performing care and conducting treatment

by a doctor

18. Possibility of repeated consultations with the same doctor

19. Waiting time for diagnostic test results

$\begin{array}{lllll}\mathbf{0 . 4 6} & 0.32 & 0.23 & \mathbf{0 . 4 9} & 0.11\end{array}$

$\begin{array}{lllll}0.56 & 0.17 & 0.37 \quad 0.07\end{array}$

$\begin{array}{lllll}0.20 & 0.51 & 0.27 & 0.29 & 0.15\end{array}$

20. Improvement in health condition (reduced symptoms, pain)

21. Improvement in emotional state (reduced fears, concerns)

$\begin{array}{lllll}0.15 & 0.09 & 0.13 & 0.15 & \mathbf{0 . 8 3}\end{array}$

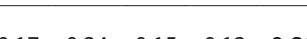

22 . Return to routine activities

$\begin{array}{lllll}0.12 & \mathbf{0 . 4 5} & 0.03 & 0.04 & \mathbf{0 . 6 0}\end{array}$

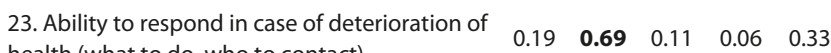
health (what to do, who to contact)

24. Motivation to follow recommended treatment

0.19 .690 .110 .060 .33

\begin{tabular}{lllllll}
\hline 25. Treatment of patients by auxiliary staff & 0.16 & 0.16 & $\mathbf{0 . 7 8}$ & 0.04 & 0.08
\end{tabular}

\begin{tabular}{lllllll}
\hline 26. Waiting time for diagnosis and treatment & 0.22 & 0.43 & $\mathbf{0 . 5 2}$ & 0.17 & 0.10
\end{tabular}

\begin{tabular}{lllllll}
\hline 27. Nurses' professionalism and their relations & 0.21 & 0.05 & $\mathbf{0 . 8 1}$ & 0.06 & 0.06
\end{tabular} with patient (kindness, patience, diligence)

28. Providing information about disease

prevention and a healthy lifestyle by a doctor $\begin{array}{llllll}0.21 & \mathbf{0 . 5 1} & 0.35 & 0.11 & 0.18\end{array}$ or nurse

Factor loadings of 0.45 or higher are shown in bold, indicating the item's main loading

urban) and patient satisfaction were identified with regard to 3 out of 5 domains of hospital care, and in each case rural patients received higher scores than their urban counterparts. The 3 domains were as follows:

1) satisfaction with hospital settings and staff care $(b=0.145$; $\mathrm{SE}=0.052 ; p=0.005)$;

2) satisfaction with doctors' professional skills $(b=0.103$; $\mathrm{SE}=0.052 ; p=0.045)$; 
Table 4. Association between place of residence (rural vs urban) and patient satisfaction

\begin{tabular}{|c|c|c|c|c|c|c|}
\hline & \multicolumn{3}{|c|}{ Model $1^{\mathrm{a}}$} & \multicolumn{3}{|c|}{ Model $2^{b}$} \\
\hline & $b$ & $S E$ & $p$ & $b$ & $S E$ & $p$ \\
\hline Doctors' interpersonal skills & -0.034 & 0.052 & 0.510 & -0.039 & 0.054 & 0.478 \\
\hline Patients' empowerment & 0.034 & 0.052 & 0.514 & -0.009 & 0.055 & 0.870 \\
\hline Hospital settings and staff care & 0.145 & 0.052 & 0.005 & 0.105 & 0.054 & 0.051 \\
\hline Doctors' professional skills & 0.103 & 0.052 & 0.045 & 0.083 & 0.055 & 0.128 \\
\hline Hospitalization outcomes & 0.120 & 0.052 & 0.020 & 0.121 & 0.055 & 0.028 \\
\hline
\end{tabular}

3) satisfaction with hospitalization outcomes $(b=0.120$; $\mathrm{SE}=0.052 ; p=0.020$ ).

After adjustments for socio-demographic variables, the association remained significant only with regard to satisfaction with hospitalization outcomes $(b=0.121$; $\mathrm{SE}=0.055 ; p=0.028)$.

\section{DISCUSSION}

The factors affecting patient satisfaction are complex and can be investigated from various perspectives. The presented study examined whether place of residence (rural/urban) differentiated patient assessment of satisfaction with hospital health care. The comparative assessment of 28 satisfaction items revealed more similarities than differences between the rural and the urban samples. Significant differences in satisfaction were identified only in relation to 9 items. In every case, rural respondents ranked the respective items slightly higher than their urban counterparts. The obtained findings are in concordance with other studies that show better experiences with health care services among rural populations $[3,17]$.

Since patient satisfaction is a multifaceted concept, an exploratory factor analysis was used to uncover the underlying structure of the questionnaire, and accordingly, reduce 28 satisfaction items to a fewer number of factors. The factor analysis identified 5 factors accounting for $63.16 \%$ of variance: (1) doctors' interpersonal skills, 2) patients' empowerment, 3) hospital settings and staff care, 4) doctors' professional skills, and 5) hospitalization outcomes. Exploratory factor analysis is a helpful tool for investigating variable relationships for complex constructs, such as patient satisfaction, and is often used in patient satisfaction analyses $[10,26]$. The 5 dimensions of hospital health care that were distinguished by factor analysis correspond with components of inpatient satisfaction identified in other studies $[2,5,7]$.

The results of regression analysis indicated that rural patients had better overall experiences with hospital settings and staff care, doctors' professional skills, and hospitalization outcomes. Due to significant differences in background characteristics between the rural and the urban samples, multivariate models adjusted for socio-demographic variables were run to eliminate confounding effects of these variables. Interestingly, after controlling for covariates, the association between place of residence and satisfaction remained significant only with regard to hospitalization outcomes, namely, improvement in the physical and emotional condition, and return to routine activities.

Even though there may be other potentially confounding variables, it can be cautiously assumed that place of residence independently affects how patients assess satisfaction with hospitalization outcomes. There may be several possible explanations why rural respondents were more satisfied with the results of hospitalization. Since the research was conducted in large, urban hospitals, rural patients could have been more satisfied from the very start of hospitalization, just because they had been admitted to an advanced medical facility. As noted by Levinton et al., patients who receive care outside their place of residence may be more inclined to report higher satisfaction, because they need to obtain specialized services not available nearby [17]. Possibly, in the current study, rural patients may have indicated satisfaction with hospitalization outcomes somewhat in advance, without observing an actual improvement in the health condition. In addition, higher dissatisfaction among urban patients could have been the result of better accessibility to health care services. Due to more options to choose from, urban patients may assume that other medical facilities located in their city offer better care [17]. Therefore, in comparison with their rural counterparts, the urban patients demand for high quality care will be greater and more challenging. From this perspective, higher satisfaction with hospitalization outcomes among rural patients could result from overall lower expectations for health care service quality.

Some limitations of this study should be pointed out. Since the questionnaire included only basic background variables, one limitation is the lack of in-depth socio-demographic characteristics of the study sample. As seen in the study, in most cases the associations between place of residence and patient satisfaction disappeared when the background variables were entered into the analysis. Therefore, it cannot be excluded that the urban-rural disparity in satisfaction with hospitalization outcomes would no longer be valid after controlling for other confounders not included in the study. Another potential limitation of the current study is that it was not known whether the respondents who declared living in an urban location, were hospitalized locally or in a different city. Thus, it may be difficult to argue that rural patients reported higher satisfaction with hospitalization outcomes because only they received care outside their place of residence.

\section{CONCLUSIONS}

Some evidence for differences in patient satisfaction by place of residence was found. Compared with their urban counterparts, rural patients had better overall experiences with hospital settings and staff care, doctors' professional skills, and hospitalization outcomes. However, location difference (rural/urban) was independently associated with patient satisfaction only in relation to hospitalization outcomes. The obtained results confirm the potential importance of incorporating background characteristics in satisfaction outcome analyses. The study findings may be used by health care providers to address gaps in patients' unmet expectations with health care services by implementing care quality improvement programs. 


\section{REFERENCES}

1. Ferrand YB, Siemens J, Weathers D, Fredendall LD, Choi Y, Pirrallo RG, et al. Patient satisfaction with healthcare services. A critical review. Qual Manag J. 2016; 23(4): 6-22. doi: 10.1080/10686967.2016.11918486

2. Kraska RA, Weigand M, Geraedts M. Associations between hospital characteristics and patient satisfaction in Germany. Heal Expect. 2017; 20(4): 593-600. doi: 10.1111/hex.12485

3. Yaya S, Bishwajit G, Ekholuenetale M, Shah V, Kadio B, Udenigwe O. Urban-rural difference in satisfaction with primary healthcare services in Ghana. BMC Health Serv Res. 2017; 25; 17(1): 776. doi: 10.1186/ s12913-017-2745-7

4. Sixma HJ, Kerssens JJ, Campen CV, Peters L. Quality of care from the patients' perspective: from theoretical concept to a new measuring instrument. Health Expect. 1998; 1(2): 82-95.

5. Bjertnaes OA, Sjetne IS, Iversen HH. Overall patient satisfaction with hospitals: Effects of patient-reported experiences and fulfilment of expectations. BMJ Qual Saf. 2012; 21(1): 39-46. doi: 10.1136/ bmjqs-2011-000137

6. Xesfingi S, Vozikis A. Patient satisfaction with the healthcare system: Assessing the impact of socio-economic and healthcare provision factors. BMC Health Serv Res. 2016; 16(94). doi: 10.1186/s12913-0161327-4

7. Schoenfelder T, Klewer J KJ. Determinants of patient satisfaction: a study among 39 hospitals in an in-patient setting in Germany. Int J Qual Health Care. 2011; 23(5): 503-509. doi: 10.1093/intqhc/mzr038

8. Batbaatar E, Dorjdagva J, Luvsannyam A. Conceptualisation of patient satisfaction: a systematic narrative literature review. Perspect Public Health. 2015; 135(5): 243-250. doi: 10.1177/1757913915594196

9. Weinhold I, Gurtner S. Rural - urban differences in determinants of patient satisfaction with primary care. Soc Sci Med. 2018; 212: 76-85. doi: 10.1016/j.socscimed.2018.06.019

10. Riedl, D, Schüßler G. The influence of doctor-patient communication on health outcomes: a systematic review. Z Psychosom Med Psychother. 2017; 63(2): 131-150. doi: 10.13109/zptm.2017.63.2.131.

11. Crow R, Gage H, Hampson S, Hart J, Kimber A, Storey L, et al. The measurement of satisfaction with healthcare: implications for practice from a systematic review of the literature. Health Technol Assess. 2002; 6(32): 1-244.

12. Quintana JM, González N, Bilbao A, Aizpuru F, Escobar A, Esteban C, et al. Predictors of patient satisfaction with hospital health care. BMC Health Serv Res. 2006; 6: 1-9. doi: 10.1186/1472-6963-6-102.

13. Buchanan RJ, Wang S, Stuifbergen A, Chakravorty BJ, Zhu L, Kim M. Urban/rural differences in the use of physician services by people with multiple sclerosis. NeuroRehabilitation. 2006; 21(3): 177-187.
14. Yan Z, Wan D, Li L. Patient satisfaction in two Chinese provinces: Rural and urban differences. Int J Qual Heal Care. 2011; 23(4): 384-389. doi: 10.1093/intqhc/mzr03

15. Henning-Smith C, Prasad S, Casey M, Kozhimannil K, Moscovice I. Rural-Urban Differences in Medicare Quality Scores Persist After Adjusting for Sociodemographic and Environmental Characteristics. Rural Health. 2019; 35(1): 58-67. doi: 10.1111/jrh.12261

16. Laksono AD, Wulandari RD, Soedirham O. Urban and Rural Disparities in Hospital Utilization among Indonesian Adults. Iran J Public Health. 2019; 48(2): 247-255. doi: 10.18502/ijph.v48i2.819

17. Levinton C, Veillard J, Slutsky A, Brown A. The importance of place of residence in patient satisfaction. Int J Qual Heal Care. 2011; 23(5): 495-502. doi: 10.1093/intqhc/mzr048

18. Mollica MA, Weaver KE, McNeel TS, Kent EE. Examining urban and rural differences in perceived timeliness of care among cancer patients: A SEER-CAHPS study. Cancer. 2018;124 (15): 3257-3265. doi: $10.1002 / \mathrm{cncr} .31541$

19. Macintyre S, Ellaway A, Cummins S. Place effects on health: how can we conceptualise, operationalise and measure them? Soc Sci Med. 2002; 55(1): 125-139. doi: 10.1016/S0277-9536(01)00214-3

20. Hart LG, Larson EH, Lishner DM. Rural definitions for health policy and research. Am J Public Health. 2005; 95(7): 1149-1155. doi: 10.2105/ AJPH.2004.042432

21. Wallace LS, DeVoe JE, Bennett IM, Roskos SE, Fryer GE Jr. Perceptions of healthcare providers' communication skills: Do they differ between urban and non-urban residents? Health Place. 2008; 14(4): 653-660. doi: $10.1016 /$ j.healthplace.2007.10.010

22. Henning-Smith C, Kozhimannil K, Casey M, Prasad S, Moscovice I. Rural-Urban Differences in Medicare Quality Outcomes and the Impact of Risk Adjustment. Med Care. 2017; 55(9): 823-829. doi: 10.1097/ MLR.0000000000000761

23. Li J, Shi L, Liang H, Ding G, Xu L. Urban-rural disparities in health care utilization among Chinese adults from 1993 to 2011. BMC Health Serv Res. 2018; 18(1): 102. doi: 10.1186/s12913-018-2905-4

24. Rahmqvist M, Bara AC. Patient characteristics and quality dimensions related to patient satisfaction. Int J Qual Heal Care. 2010; 22(2): 86-92. doi: 10.1093/intqhe/mzq009

25. Haddad S, Potvin L, Roberge D, Pineault R, Remondin M. Patient perception of quality following a visit to a doctor in a primary care unit. Fam Pract. 2000; 17(1): 21-29. doi: 10.1093/fampra/17.1.21

26. Zinn W, Sauer S, Göllner R. The German Inpatient Satisfaction Scale: a large-scale survey of perceived quality by inpatients', SAGE Open. 2016. doi: $10.1177 / 2158244016643140$ 